\title{
El clima del aula: un abordaje desde la ética*
}

\author{
Maria del Rosario Cora Mercadal**
}

\begin{abstract}
"A título de ejemplo, la enseñanza de la ética (curiosa pretensión), creación de actitudes, fomento de hábitos, etc. son objeto de regulación administrativa, intenciones del currículum que acaban siendo sometidas a los mismos patrones de la enseñanza dominante que afectan a cualquier otro contenido".
\end{abstract}

J. Gimeno Sacristán, 1989; 67

\begin{abstract}
The consideration of atmosphere classroom as didactic and pedagogic problematic boarded from he ethic, searches a different look and, although the difficulty is the area in which is surrounded finds reasonable justification to go ahead. When we enter to de classroom it is recognised, in the complex scene of contextual zed, autobiographic, subjective, cultural and historic condition two dimensions of our ethic and moral acting: balance and negotiation with the ethic and moral ideological blocks which we are given from outside, and the progressive affirmation of an acting in the world based in principles and rules, product of our own individual elaboration, that is, the capacity of being the manager of one's own affairs. Both require to build moral personality or a subjectivity of certain strength to face the world which, for our pupils, is the school and the classroom.
\end{abstract}

\section{Resumen}

La consideración del clima de aula como problemática pedagógica y didáctica abordada desde la ética, busca una mirada diferente y, aunque la dificultad radica en el área que la encuadra, encuentra razonable justificación para seguir adelante. Al entrar en las aulas se reconoce en ese complejo cuadro de condiciones contextuales, autobiográficas, intra subjetivas, culturales e históricas dos dimensiones de nuestro actuar ético y moral: el balance y ajuste de cuentas con los núcleos éticos y morales que nos son dados, lo que nos viene de afuera, y la afirmación progresiva de un actuar en el mundo con base en principios y reglas, fruto de nuestra propia elaboración individual, es decir, la capacidad de ser autónomo y autorregulado. Ambas, requieren construir una personalidad moral o una subjetividad de cierto carácter y fortaleza para enfrentar el mundo el cual, para nuestros alumnos, no es otro que la escuela y el salón de clase.

\section{1- I ntroducción}

Este trabajo se basa en la investigación llevada a cabo en tres escuelas del departamento de Florida(Uruguay) entre mayo y noviembre de 2004 y se presenta como informe de tesis para la obtención de Maestría en Educación de la Universidad ORT.

Toda educación tanto significa para el educador como para el educando la recepción o transmisión de un saber social previamente existente, que más allá de su especificidad técnica o de su utilidad práctica, viene cargado de un sentido contextual. Todo saber responde a 
representaciones colectivas que, en mayor o menor grado, incorporan pulsiones valorativas sobre el mundo objetivo y subjetivo. Por ello, para el educando, todo acto educativo implica un ejercicio de socialización en el que se incorpora al torrente de un mundo ya existente, cargado de contenidos, de jerarquías, de escalas valorativas y de evidentes y apreciables núcleos morales, normativos, unas veces represivos y otras, permisivos.

La actividad educativa no es un acto unilateral de transmisión o de incorporación pasiva de saberes y conocimientos. La educación es sobre todo un proceso mediante el cual el propio sujeto crea y recrea los sentidos del conocimiento.

Al reconocer ese complejo cuadro de condiciones contextuales, autobiográficas, intra subjetivas, culturales e históricas sabremos que siempre se nos presentarán dos dimensiones de nuestro actuar ético y moral: la primera, el balance y ajuste de cuentas con los núcleos éticos y morales que nos son dados, lo que nos viene de afuera, es decir, frente aquello ante lo cual, en mayor o menor medida, seremos heterónomos y la segunda, la afirmación progresiva de un actuar en el mundo con base en principios y reglas, fruto de nuestra propia elaboración individual, es decir, la capacidad de ser autónomo, autorregulado y responsable e imputable único de nuestros propios comportamientos prácticos. Ambas dimensiones requieren construir una personalidad moral o una subjetividad de cierto carácter y de cierta fortaleza o ánimo para enfrentar el mundo que, para nuestros alumnos, no es otro que la escuela y el salón de clase.

La relevancia del tema desde el punto de vista didáctico permite una mirada diferente de la realidad de cada día de las aulas; desde el planteo del problema, sus objetivos y sus propósitos la dificultad que plantea radica en el área que lo encuadra, la ética y la moral. Aun así se encuentra una razonable justificación que permite seguir adelante. El carácter específico que hemos señalado al conocimiento social y a la autorepresentación del mundo moral que elaboran los grupos humanos, el conocimiento de un sentido ético y moral del mundo pasa, en mayor o menor medida, por un grado de apropiación, validación, adecuación, rechazo y construcción de sentidos propios y personales del comportamiento moral y ético.

La fortaleza de una conducta moral está más dada por la interiorización, por el reconocimiento íntimo de su validez, justeza o pertinencia, antes que por la mera repetición mecánica. Por mucho que nos imaginemos el comportamiento más heterónomo posible de un joven o de un adulto, habrá momentos en el que frente a situaciones cambiantes, el sujeto en cuestión, tendrá que tomar una decisión con un grado mínimo pero existente de elección voluntaria, de convencimiento y de pasión, es decir, en otras palabras, con un grado rudimentario de conciencia subjetiva del trance en el que se halla. Trance en el que tendrá que elegir entre los comportamientos posibles y las consecuencias esperables.

Entonces la Formación Ética y Moral debe ser asumida por la escuela como un reto tendiente a generar cambios en las relaciones que se dan dentro de ella para dotarla de un nuevo sentido; hacer un ejercicio de desconstrucción-reconstrucción cultural, para definir qué se debe cambiar y qué debe permanecer dentro de la escuela que tenemos, en la perspectiva de construir colectivamente nuevos modelos de convivencia social basados en una nueva cultura escolar.

Dicho reto debe llevar a pensar la institución educativa como laboratorio social en la cual se propicien experiencias para el reconocimiento del otro, la aceptación de la diversidad cultural, la tolerancia, la búsqueda de modelos de convivencia y la negociación como mecanismos para el tratamiento de los conflictos, en la perspectiva del consenso y la concertación.

\section{8 - Universidad ORT Uruguay}


En este sentido la reflexión debe reflejar el carácter plural y polifónico de este debate y debe permitir que los miembros de la comunidad educativa tengan la oportunidad de conocer las distintas concepciones sobre la ética que concurren a la discusión, para que sean ellos quienes determinen con cuál concepción y cuál proyecto ético se comprometen.

Sobre la multiplicidad de expresiones de lo moral, en las que se entrecruzan sentimientos, actitudes, preferencias, intuiciones, gustos, sentidos, ideales, significados, acciones, saberes, intereses, costumbres, hábitos etc., es necesario construir el posible papel del docente, reconociendo las diversas demandas que le hacen los niños y la institución, y planteándole la pregunta sobre su desempeño como educador moral. Es la comprensión del complejo entramado social de la escuela, lo que demanda al maestro acercarse al cómo suceden y por qué suceden diferentes situaciones que componen el llamado clima de aula

\section{2- Aportes teóricos}

\section{1- La moral en la escuela}

Cualquier sistema de educación, cualquier teoría pedagógica, cualquier política educativa que le reste a la escuela el papel de la formación ética de sus estudiantes fracasa en una de sus funciones primarias: deberían analizarse entonces las prácticas cotidianas de la misma desde la perspectiva de qué contribución hacen a la formación de las personas.

Así entra en el debate y en la discusión el tema de la educación moral y la moral en cuanto su valor, su contenido, su didáctica y su fin. Encontramos diversos modelos y abordajes que se desarrollan teóricamente entre lo individual y lo social, entre la autonomía y la heteronomía, entre lo autoritario y lo reflexivo, entre la intervención familiar, institucional y social, entre lo prescripto y lo creado.

J. Bruner (1997), expresa que hay otras formas de aprender más allá de la memorización y que se basan en la creación de condiciones de consentimiento consciente como la comprensión, apreciación, entendimiento, captación. Los contenidos a enseñar son parte de grandes totalidades, son contenidos dentro de marcos envolventes de significación epistémica.

Estas superestructuras epistémicas se refieren a algo holístico y representan una unidad de comprensión humana más o menos definida y distinguible, cada una de ella designa algo que puede estudiarse y enseñarse de un modo organizado. Por lo tanto, desde el punto de vista pedagógico, los aspectos relacionales y contextuales resultan ser tan significativos como los propios hechos y destrezas. Bruner (1997) sostiene que es más importante estudiar los lineamientos de estas estructuras mayores que los conocimientos más sustantivos en ellas.

\section{2- Los trabajos de Philip Jackson}

La lectura de sus libros incrementan la sensibilidad y la reflexión consciente acerca de la influencia que ejercen los aspectos morales en lo que sucede en clase. La enseñanza, como interacción humana, es una empresa moral que implica aspectos de imparcialidad, justicia, corrección y virtud, definiéndose no tanto por las capacidades técnicas de los profesores sino por las intenciones educativas y propósitos morales que comprenden su trabajo. Un análisis de la enseñanza no podrá, entonces, obviar dar cuenta y comprender esta dimensión moral, intrínseca a cualquier práctica educativa.

En el sentido más práctico y moderno Jackson (2002) nos muestra cómo lo cotidiano, lo simple y lo natural del ambiente escolar y su entorno se transforma en insumo valioso para el tratamiento de temas y contenidos que pertenecen a la formación ética de los alumnos. 
A través de sus reflexiones, de su historia personal y del estudio de las imbricadas relaciones que se establecen en la situación de enseñanza y de aprendizaje nos permite descubrir la complejidad del entramado histórico, social y moral -individual y colectivo- que implica la escuela o el salón de clase.

Sobre el buen clima escolar como parte integrante de la formación moral de los alumnos Jackson (2002) observa cómo los docentes para disipar su incertidumbre pedagógica en cuanto sus logros en el aula, (que van más allá de lo libresco y tienen que ver con lo que sucede en ese lugar), recorren con la vista el salón en busca de signos espontáneos de comprensión, de interés y de aprobación que le trasmiten sus alumnos a través de gestos y posturas o tratan de percibir algo menos evidente que es "la atmósfera de aula", esa invisible red en la que se tejen variados elementos que son el motivo de nuestra investigación.

Más interesante aun resulta reconocer en los recuerdos del propio Jackson (2002) cuestiones tan ricas como el compromiso moral de los docentes con los alumnos y de éstos con sus maestros más allá del tiempo; el recuerdo y admiración por los maestros que le formaron y su deuda hacia los mismos, la visualización de aquellos docentes pletóricos de emoción y entusiasmo que logran despertar e inspirar actividad mental alerta e intensa a quienes entran en sus salones de clase; la excelente oportunidad que puede dar la escuela para que las capacidades de cada uno afloren y "fructifiquen" y el rescate de lo que hace la enseñanza al docente en cuanto la afloramiento de agradables cualidades y al que la enseñanza ha marcado la vida de Jackson (1990) en aspectos por los que estará por siempre agradecido y que le han permitido comprender los efectos de la escolaridad en todos los que participan en ella, los docentes y los alumnos por igual.

En su obra "La vida moral en la escuela" (Jackson et al, 2003) encontramos un enfoque novedoso de la vida cotidiana en el aula y un modo de ver y considerar los sucesos del aula que posibilita poner de relieve su significación moral y expresiva. Además de las actividades explícitamente dirigidas a tal fin, hay otros aspectos (desde la decoración de la clase a las expresiones del rostro de los docentes) que justamente tienen una incidencia y significación moral, pasando normalmente inadvertidos por formar parte de la subestructura curricular.

En los últimos años, después de un período de objetivismo que pretendía romper con el adoctrinamiento ideológico de otros momentos, se está reivindicando la naturaleza intrínsecamente moral de la educación. En este final de la modernidad, tras la etapa racionalista en la que todo el interés se concentraba en cómo planificar (racionalizar) la actividad docente para conseguir determinados resultados, estamos volviendo a recuperar el ángulo personal del oficio de maestro, desde el cual el asunto se juega más en el compromiso personal, la vocación y la entrega por realzar educativamente la vida de los alumnos. La enseñanza, más que mera instrucción, es interrelación de personas, guiada por metas morales, de modo consciente (actividades explícitamente dirigidas a la educación moral) o, como suele ser más frecuente, implícitamente por la vida en las aulas (mediante el currículum "oculto").

Se trata de cómo mirar y observar la vida moral del aula sin moralizar, redirigiendo la mirada de los observadores, como artistas que muestran y aprecian los significados y valores de las expresiones, de acciones o hechos.

Se adopta un deliberado propósito de mantenerse en un plano descriptivo, sin deslizarse por escurridizos caminos prescriptivos, por lo que "no debemos esperar que de este enfoque surjan recetas prácticas" (Jackson et a, 2003).

\section{0 - Universidad ORT Uruguay}


De ahí que, contra lo que suele ser habitual en libros sobre educación moral, Jackson, Boostrom y Hansen (2003) renuncien a propuestas normativas o curriculares sobre cómo debía ser la educación moral. Además, operan con una segunda restricción: limitarse a la observación de lo que pasa, sin preguntar a los docentes sobre lo observado, evitando que tengan que justificar los hechos. Esta posición pretende, al tiempo, restringir las observaciones a lo efectivamente visto u oído, colocando al observador en una perspectiva más cercana a la vivida por los alumnos, quienes tampoco suelen preguntar a sus maestros el por qué de sus actuaciones. Si las observaciones etnográficas precisan de una hermenéutica que les dé sentido y significado, de ellas no se deducen directamente guías sobre lo que deba hacerse moralmente. No obstante, incrementar la sensibilidad y el conocimiento de la vida moral del aula, inevitablemente, lleva a que los maestros tengan presentes dichas dimensiones en su práctica docente y les interese esa realidad escondida o invisible.

Estos autores ponen de manifiesto cómo todo proceso interactivo de las aulas y centros, desde los niveles más explícitos a implícitos, es intrínsecamente una actividad moral, no tanto por los contenidos que se enseñen sino por la forma misma en que se regulan y expresan. Al describir etnográficamente las percepciones de la enseñanza por los maestros, se manifiesta hasta qué grado están repletas de consideraciones morales. Se ven a sí mismos como modelos de buena conducta y como guías en el arriesgado terreno moral. Estos docentes, aun sin ser totalmente conscientes de ello, siempre son educadores morales. Sus comentarios en clase, sus maneras de organizarla, conducta, modos de tratar o evaluar a los alumnos, implícita o explícitamente educan en valores y actitudes, como han mostrado los análisis sobre el "currículum oculto", del que el propio Jackson fue iniciador. Por eso más vale planteárselas crítico-reflexivamente, que dejarlas al arbitrio del azar, siempre reproductor de las relaciones sociales vigentes.

En la primera parte de la obra ya citada (En busca de la moral: una guía para el observador) establecen una guía de observación, a modo de taxonomía de categorías de influencia moral dentro de las aulas. Se trata de ofrecer sugerencias sobre dónde buscar la moral y, en particular, perspectivas sobre el modo de observar las implicaciones morales en la trama del aula, más allá de lo explícito. Un primer conjunto comprende cinco categorías expresamente morales, como intentos deliberados de promover la educación moral: la educación moral como una parte formal del currículum; la educación moral dentro del currículum; rituales y ceremonias; muestras visuales de contenido moral; manifestaciones espontáneas de comentarios morales en la actividad en curso. Por su parte, el segundo conjunto lo constituyen prácticas de la vida del aula y cualidades de los docentes que encarnan, en muchas ocasiones indirectamente, una posición moral. Este segundo grupo lo forman dimensiones que incorporan implícitamente la moral y son, por eso, menos obvias, obligando a ir más allá de los hechos, afectando -no obstante- de modo más importante a la educación moral de los alumnos. Las categorías de este segundo grupo son: normas y regulaciones del aula, la moralidad de la subestructura curricular y moralidad expresiva en el aula.

Los autores proponen esta guía de observación organizada en categorías, con sus correspondientes especificaciones en cada una, como ayuda para ver y observar en qué grado la enseñanza es una empresa moral, llamando la atención a las maneras múltiples como se manifiesta lo que se ve, oye o vive en el aula. Aparte de la delimitación de categorías con propósito deliberado de educación moral del primer grupo, la importancia del segundo conjunto es mostrar los resultados no intencionales de la enseñanza que resultan más eficaces, en la medida que permanecen a lo largo de la práctica: "las normas que estructuran la clase, los supuestos en que se basa el currículum y el estilo o carácter del docente están casi siempre presentes" (Jackson et al, 65). 
Además de dirigir la mirada a lo que ocurre en el aula, se precisa reflexionar sobre lo visto para extraer su significación moral. La segunda parte (Advertir la complejidad moral dentro de un ámbito escolar: cuatro series de observaciones) trata de ofrecer ejemplos de este proceso reflexivo, en el que se distinguen dos fases: una descriptiva, que se produce durante la observación del aula, y una etapa posterior de reflexión sobre lo observado. Ambas fases se encuentran mediadas por la interpretación de los hechos, pues la lectura moral de lo que vemos cuando observamos el mundo de la enseñanza es una obra abierta (recurriendo a la terminología de Umberto Eco), sujeta a sucesivas reconstrucciones e interpretaciones.

En esta parte se incluyen fragmentos seleccionados de observaciones, seguidos de los comentarios pertinentes sobre las actuaciones docentes en distintos ámbitos. El análisis de los fragmentos apunta siempre a desvelar la posible significación moral de los sucesos descritos. Más que juzgar moralmente la bondad o no de las acciones, se trata de revelar ("comprensión expresiva") su significado moral. Así señalan... "lo que nos interesaba era cómo ver lo moral o lo inmoral, no sólo en lo que los docentes dicen y hacen, sino también en otros aspectos de la vida en el aula. Nuestro objetivo, en otras palabras, nunca fue demostrar las buenas intenciones morales del docente común, ni averiguar si los docentes específicos con quienes trabajamos eran básicamente buenas personas. Dimos por descontadas ambas cosas desde el comienzo. Nuestra meta era descubrir cómo había que proceder para discernir las propiedades morales de los docentes y las aulas en general, con la convicción de que existían y que podían revelarse". (Jackson et al,2003,138).

La tercera parte (Enfrentar la ambigüedad y la tensión morales: otras series de observaciones) recoge otras observaciones efectuadas en distintos establecimientos sobre el medio físico y la experiencia global de los alumnos, que penetran, en este caso a un nivel mayor de profundidad, en la trama y urdimbre de las prácticas pedagógicas. La ambivalencia de la vida moral en el aula muestra que, aun en el caso de buenos docentes, se dan también una serie de prácticas cuestionables. Las continuas observaciones ilustran la complejidad de la vida moral en las aulas. De este modo declaran: "En conjunto, estos cambios en nuestra percepción equivalen a lo siguiente: cuanto más observábamos y más reflexionábamos sobre lo que veíamos y oíamos, más conciencia tomábamos de la insondable complejidad de la vida en el aula; más respeto nos merecían los docentes a quiénes observábamos en nuestras visitas, y algo de gran importancia en el presente contexto: más nos convencíamos de que nuestro procedimiento de observar y luego reflexionar sobre la expresividad de lo visto y oído nos ayudaba a desentrañar las dimensiones morales de gran parte de lo que sucedía en las aulas visitadas". (Jackson et al, 2003, 256).

Por su parte, en la última parte (Cultivar la conciencia expresiva en aulas y escuelas) se dedican a explicar, a modo de conclusiones e implicaciones, el fundamento, el proceso y los beneficios potenciales del enfoque adoptado. Entienden como "conciencia expresiva" tener una sensibilidad moral activa acerca los fenómenos morales que se expresan de modo complejo en el aula. En primer lugar, se recogen un conjunto de orientaciones sobre los modos de mirar los sucesos en el aula (mantenerse abierto a lo imprevisto, cultivar la mirada y el oído para lo problemático, incluirse a sí mismo entre los sujetos observados, etc.) de forma que vayan más allá de la contemplación pasiva. Además de exigir la inversión de mucho tiempo, cambia a lo largo del proceso. Un camino desafiante recorre la observación y su posterior análisis. Lo expresivo moralmente está en todas partes, pero especialmente en los detalles, por lo que se requiere mirar con detenimiento, tratándolos como símbolos que contienen un significado moral. Una actitud favorable contribuye a que la mirada detenida pueda observar lo que se expresa de modo sutil.

\section{2 - Universidad ORT Uruguay}


La lectura del libro conduce a incrementar la "conciencia expresiva" de los docentes, al volverse conscientes de la significación moral de los propios actos y del clima que contribuyen a crear en sus lugares de trabajo. Alejarse, en parte, de la acción inmediata para reflexionar sobre la misma, puede contribuir a incrementar el compromiso con lo que se hace, al apercibirse de las significaciones morales de muchas acciones que permanecían invisibles.

Los asuntos morales no tienen que ser importados al aula, como si la enseñanza debiera adquirir un carácter moral, este libro muestra que está ya saturada de dicho significado. Las acciones que el maestro desarrolla en clase, según su manera, estilo o tacto, expresan un significado moral y, como tales, influyen en los alumnos, en el presente y en el futuro.

Para terminar ofrecen sugerencias de nuevas lecturas, divididas en temas y seleccionando varios textos comentados a los que pueden recurrir los lectores para ir más lejos del libro en temas como la expresión y las cualidades expresivas; perspectivas sobre la moral; las escuelas y la enseñanza; los docentes y las prácticas de enseñanza.

La lectura de sus libros incita a descubrir el significado moral de la escuela; traspasar este primer umbral descriptivo sería avanzar en tareas explicativas de la moral en la enseñanza, en la postura del docente, en las conductas de los alumnos y en las percepciones de los padres hacia la escuela.

En su publicación de Llamados a enseñar (Hansen, 2001) y Explorando el corazón moral de la enseñanza(Hansen, 2002) aborda aspectos relacionados con la vocación docente y la proyección del quehacer de los docentes en las aulas y la vida institucional, bibliografía que abordaremos con intensa curiosidad.

\section{3- Convivencia y disciplina}

Es tal la trascendencia educativa de la convivencia y la disciplina en la clase, que cualquier docente que se precie de tal cuida con especial esmero que se desarrolle en las mejores condiciones de orden y eficacia, pues una clase no sólo es un lugar donde se imparten enseñanzas y se llevan a cabo determinados aprendizajes, sino también, y muy principalmente, es el momento oportuno de promover y desarrollar los valores humanos en los escolares.

La disciplina es un hábito interno que facilita a cada persona el cumplimiento de sus obligaciones y su contribución al bien común. Así entendida, la disciplina es autodominio, capacidad de actualizar la libertad personal; esto es, la posibilidad de actuar libremente superando los condicionamientos internos o externos que se presentan en la vida ordinaria, y de servir a los demás.

El maestro crea un ambiente donde tienen cabida las palabras y gestos que adquieren especiales significaciones en ese contexto casi íntimo y propio en el cual el alumno se hace consciente de que forma parte de un grupo que lo acepta como tal y se ve a sí mismo como un elemento de la comunidad grupal.

Los padres suelen plantear que la disciplina y el orden son valores fundamentales en un centro escolar, no sólo porque mejorar facilitar el aprendizaje, sino porque constituyen, en sí mismos, una excelente lección. Una clase en que se rompe la estructura de alineación y de silencio del grupo frente al maestro y en la que se toman decisiones de forma compartida, en la que se forman grupos de discusión, en la que se negocian las normas, el maestro disminuye su poder de decisión y se convierte en facilitador de la tarea compartida. Con todo esto, las redes de relaciones alumno-alumno se potencian, multiplican e intensifican; el valor más 
importante no es el del silencio, sino el del trabajo compartido. La modificación de los planteamientos existentes sobre disciplina en las aulas y en los centros, supone realizar una transformación de la mentalidad y de la concepción del currículo en sus fundamentos morales y éticos.

\section{4- La autonomía moral}

La mayor parte de nosotros provenimos de escuelas (y de familias) autoritarias en las que se esperaba que con disciplina estricta, con medidas severas se respetaran las reglas y se pretendía encasillarnos dentro de un molde en lugar de desarrollar nuestra autonomía.

Así, el desarrollo de la autonomía significa llegar a ser capaz de pensar por sí mismo con sentido crítico, teniendo en cuenta muchos puntos de vista tanto en el ámbito moral como en el intelectual. Jean Piaget (1952) señala que la autonomía aparece con la reciprocidad cuando el respeto mutuo es suficientemente fuerte para hacer que el individuo sienta el deseo de tratar a los demás como él desearía ser tratado. La autonomía moral aparece cuando la mente considera necesario un ideal que es independiente de cualquier presión externa. Por tanto, no puede haber necesidad moral fuera de nuestras relaciones con los demás.

El desarrollo moral implica un camino hacia la abstracción y va siempre unido al intelectual y emocional. Para que las realidades morales se constituyan y se desarrollen es necesario que los individuos entren en relación unos con otros. La moral, que es la realidad normativa o la conciencia del deber que el individuo impone sobre su yo, surge a partir de la educación de las relaciones entre iguales y con adultos que el individuo en desarrollo vive tanto en su familia, como en el aula o en la escuela.

Piaget (1932) sostiene que hay acuerdo entre los teóricos de la moral en que el respeto es el sentimiento fundamental que posibilita la adquisición de las nociones morales. Afirma el autor, "... mientras Kant $(1788,1790)$ ve en el respeto, un resultado de la ley, Durkheim (1893), un reflejo de la sociedad, muestra que el respeto hacia las personas es un hecho primario y que la ley misma se deriva de ese respeto". En otras palabras, "dos condiciones -dice Bovet (en Piaget, 1952) -son necesarias y suficientes para que se desarrolle la conciencia de la obligación: ....que un individuo dé a otro consignas y que este otro respete a aquél de quien emanan las consignas". Es decir, basta que ocurra el respeto a alguien para que las consignas obliguen. Si esto es así, inmediatamente se debe focalizar la educación moral, no en la enseñanza oral, teórica o inculcadora, sino atendiendo relaciones interindividuales en donde los individuos que están en contacto se consideran iguales y se respetan recíprocamente. La moral que de aquí resulta se caracteriza por un sentimiento del bien y el ideal de reciprocidad surge autónomamente. La moral de la cooperación es producto reciente de la diferenciación social y la individuación.

La propuesta de Kohlberg (1984) aparece como alternativa al modelo de adoctrinamiento o inculcación moral, (que ya ha demostrado su inoperancia), consiste en la "clarificación de valores" y se basa en el cuestionamiento y razonamiento de problemas. Tanto Piaget como Kohlberg (1984), siguiendo la tradición kantiana de la razón práctica, nos enseñan que el desarrollo moral es paralelo al intelectual y que la autonomía moral no le viene dada al sujeto, sino que éste ha de construirla, pero ambos añaden a Kant la perspectiva de la interacción y la cooperación social.

L. Kohlberg (1984) completa la investigación piagetiana con la teoría de los estadios de la evolución de la conciencia moral, elaborando una interesante aplicación pedagógica y además concibe la vida del aula como una democracia participativa y persigue el ideal de hacer de la escuela una "comunidad justa".

\section{4 - Universidad ORT Uruguay}


La teoría ética cognitivista y constructivista de Piaget (1984), y especialmente de Kohlberg (1984), es continuada y completada por la ética discursiva de J. Habermas (en Gimeno Sacristán, 1989). La ética discursiva, también denominada ética comunicativa y ética dialógica es, como la kantiana, deontológica y cognitivista; en oposición a todo emotivismo; universalista en oposición al relativismo; y procedimental por proponer el diálogo o el discurso como el procedimiento para construir y legitimar las normas correctas.

La ética discursiva añade a Kant(1788-1790), la dimensión lingüística de la comunicación discursiva. Hay un paso del monólogo al diálogo, del "yo pienso" al "nosotros argumentamos". La ética discursiva, siguiendo la herencia socrática, ha mostrado que la razón es esencialmente dialógica. "El gran acierto de la ética comunicativa ha sido descubrir que la ética es comunicación, diálogo".

La acción comunicativa, que busca el entendimiento interpersonal y el consenso racional a través del mejor argumento, es axiológicamente superior a la acción estratégica, que sólo busca el éxito a través del argumento más persuasivo. La ética discursiva se alía con una pedagogía crítica y liberadora (Giroux, 1990) y se compromete con valores como el diálogo, la colaboración, la autonomía, la democracia, la justicia o la solidaridad, que pueden servir de norte a la práctica de nuestros centros educativos que se percibe a través de variados aspectos del clima de las aulas y de las escuelas.

\section{5- Las interrelaciones en el aula}

La complejidad de la tarea docente sólo puede abordarse desde el reconocimiento del origen multicausal de los problemas de convivencia en los centros escolares. Pero el reconocimiento del diverso origen social y personal de las conductas disruptivas de un sector del alumnado no puede infravalorar la potente capacidad socializadora de la escuela, sin desconocer, al mismo tiempo, el hecho de que algunos de los problemas presentes hoy en las aulas y en los centros también tienen que ver con factores de origen escolar como el currículum, la organización y gestión del centro y del aula y el clima de la clase.

Hay varios aspectos que determinan el clima del aula, entre ellos el ambiente de aprendizaje, los procesos de comunicación y la disciplina. El orden interior, fruto de una buena organización del trabajo, favorece así mismo el desarrollo de la disciplina interna y el crecimiento personal. Un ambiente estimulante y alegre sería el mejor caldo de cultivo para el descubrimiento y la vivencia de experiencias educativas cargadas de significados.

Es, entonces, el salón de clase una comunidad en interacción donde los que participan averiguan de qué se trata el entorno y cómo se concibe el mundo; puesto que los seres humanos son los únicos que se enseñan deliberadamente unos a otros y esta especialización descansa sobre el don del lenguaje, ese talento que hace inteligible la realidad y que da significado a la experiencia. Los intercambios lingüísticos que se dan en el aula ponen de manifiesto también el don metalingüístico, "la capacidad de volvernos hacia nuestro propio lenguaje para examinar y trascender sus límites" (R.Jakobson, 1976), está al alcance de todo el mundo. Sin duda que las implicaciones pedagógicas y morales de lo anterior son obvias ya que la enseñanza que el lenguaje trasmite no es sólo la exactitud de su referencia, sino el peso de su sentido, de su semántica. Así el lenguaje insinúa, manifiesta, alude, narra, recuerda, amonesta, requiere, compara, valora, embellece, y mediante esta capacidad expresiva llega la experiencia pasada al oyente y al lector, quienes inventan nuevas experiencias sobre la base de la antigua. 
Se rechaza la versión instrumentalista del lenguaje y se acepta con Bourdieu (1977) que la acción simbólica discursiva reproduce y a su vez transforma las relaciones de poder. Entonces,"por legítimo que sea tratar las relaciones sociales como interacciones simbólicas, es decir, como relaciones de comunicación que implican conocimiento y reconocimiento, no hay que olvidar que esas relaciones de comunicación por excelencia que son los intercambios lingüísticos son también relaciones de poder simbólico donde se actualizan las relaciones de fuerza entre los locutores o los grupos respectivos" (Bourdieu, 1977). La escolarización, uno de los compromisos institucionales más tempranos fuera de la familia, crea un sistema de convivencia que implica un conjunto de normas y restricciones que juegan un papel crítico en la formación de la personalidad. Construye un sistema conceptual (el Yo) que organiza un registro de encuentros con él mismo y con el mundo: un registro que está relacionado con el pasado, pero que también está extrapolado al futuro; un yo con historia y posibilidad.

\section{6- Relación alumno-docente}

El estudio de la interacción alumno-docente ha estado presidido por los intentos de definir y medir la eficacia docente, ya fuera con fines de investigación, ya fuera para incidir en la formación de los maestros.

Consecuentemente, el interés por las características de los docentes y por los métodos que utilizan se desplaza hacia lo que ocurre efectivamente en las aulas. Este desplazamiento, ha tenido numerosas repercusiones, siendo quizás dos las más llamativas: la importancia que se concede, por primera vez, a las interacciones que se establecen entre los protagonistas de la situación educativa, y las de orden metodológico, que plantean a su vez la necesidad de disponer de instrumentos de observación potentes y objetivos.

Los sistemas de categorías, surgen en el marco de una tradición de investigación educativa en el que prima la búsqueda de relaciones entre las variables relativas al proceso de la enseñanza y las variables que hacen referencia al producto de la enseñanza, entendido como el nivel de logro de los objetivos educativos por parte de los alumnos. Este paradigma teórico acepta la observación como mal menor -puesto que no es fácil, ni tal vez posible, abordar el análisis de lo que ocurre en el aula mediante el método experimental-, es necesario hacerla tan objetiva como sea posible.

Las limitaciones inherentes al paradigma "proceso-producto" de investigación educativa y las objeciones que se formulan a los sistemas de categorías como instrumento de análisis de la interacción, no deben interpretarse, sin embargo, en términos de un rechazo absoluto de las conclusiones de los trabajos realizados en esta perspectiva. Ellas nos permiten determinar que hay dos cuestiones que parecen encontrarse fuera de discusión: la primera es que el aprendizaje escolar es sensible a la cantidad de tiempo que los alumnos dedican a tareas académicas; la segunda indica que estos aprenden más cuando sus profesores estructuran el nuevo contenido a asimilar, les ayudan a relacionarlo con lo que ya saben, controlan sus realizaciones y proporcionan las correcciones necesarias en las actividades de práctica y aplicación independiente, sean éstas individuales o colectivas.

Los procesos psicológicos implicados en la adquisición de conocimientos por parte de los alumnos, junto con otros igualmente ignorados en la perspectiva clásica, aparecen como ejes estructurales de un enfoque distinto sobre la interacción educativa por lo que conviene ante todo señalar que nos encontramos esencialmente frente a un cambio conceptual.

\section{6 - Universidad ORT Uruguay}


Entre los ingredientes básicos de estas nuevas coordenadas teóricas, hay tres que merecen, a nuestro juicio, una especial atención: la importancia creciente otorgada a la actividad constructiva de los alumnos en el aprendizaje escolar; la manera de entender el papel del docente en la aparición, mantenimiento y guía de la actividad constructiva de los alumnos; la consideración de la estructura comunicativa y del discurso educacional como uno de los elementos básicos para comprender los procesos de interacción que se dan dentro de las aulas.

Esta postura da entrada a los procesos encubiertos como elementos claves para la comprensión de los procesos interactivos que se establecen entre el docente y los alumnos en el aula.

Cabe incluir aquí los conceptos vygotskyanos para el análisis de la interacción docentealumno, que sitúan la actividad constructiva del alumno en el entramado de las relaciones sociales e interpersonales. Para Vygotsky (1984), la educación es una de las fuentes más importantes del desarrollo ontogenético en los miembros de la especie humana. El desarrollo que experimentamos los seres humanos desde el nacimiento hasta la muerte es más bien un producto, y no tanto un requisito del aprendizaje y de la educación, contrariamente a lo que se postula desde otros enfoques teóricos, se aprende y los agentes mediadores de la cultura, entre los cuales los educadores (padres, maestros, profesores, etc.) ocupan un lugar esencial. Estas ideas se traducen en dos postulados medulares de la explicación vygotskyana; la ley de la doble formación de los procesos psicológicos superiores y la educación como fuerza creadora e impulsora del desarrollo.

Según esta ley, toda función aparece dos veces: primero, a nivel social, y más tarde, a nivel individual; primero, entre personas (interpsicológica), y después en el interior del propio niño (intrapsicológica). Es importante subrayar que este proceso de interiorización progresiva implica una verdadera reconstrucción. Esta posición, no sólo no niega la actividad constructiva, sino que la integra como uno de los elementos que definen el proceso de interiorización. Esta ley referida a los procesos psicológicos superiores -desarrollo del lenguaje, atención, memoria, razonamiento, formación de conceptos, etc.-, se aplica al conjunto del desarrollo cultural del niño y es aplicable, por tanto, a la mayor parte de los contenidos escolares, incluidos los morales.

No tiene pues nada de extraño que, en esta línea de razonamiento, se vincule estrechamente la educación con la interacción, y su capacidad para crear desarrollo con el proceso de interiorización que conduce del plano interpsicológico al plano intrapsicológico.

Algunas investigaciones realizadas durante las últimas década han arrojado alguna luz sobre cómo el niño progresa a través sucesivas interacciones educativas con los adultos. Quizás sea la metáfora del "andamiaje", introducida por Bruner (1976) y sus colaboradores (Wood, Bruner y Ross, 1976), la que sintetiza mejor el conjunto de resultados y conclusiones que estamos comentando. Mediante esta metáfora se quiere significar a la vez el carácter necesario de las ayudas, de los andamios, que los agentes educativos prestan al aprendiz, y su carácter transitorio, ya que los andamios se retiran de forma progresiva a medida que el aprendiz va sumiendo mayores cotas de autonomía y de control en el aprendizaje.

Lo que sucede en el aula, lo que hacen y dicen el profesor y sus alumnos es, en gran medida, el resultado de un verdadero proceso de construcción conjunta. Como afirma Green, (en Wittrock, 1989) "los contextos de interacción son construidos por las personas al interactuar (los contextos de interacción) son construidos por las acciones de los participantes". 
Y en la encrucijada de todos estos elementos, el discurso educacional y su capacidad de mediación semiótica aparece como la pieza clave para entender de qué manera el conocimiento se presenta, se recibe, se comparte, se controla, se discute, se comprende o no por el maestro y niños en la clase.

La interacción docente-alumno aparece en la actualidad como uno de esos campos privilegiados de estudio y de investigación en los que de repente convergen aportaciones y planteamientos que se han ignorado mutuamente durante mucho tiempo y que pueden dar lugar a verdaderos saltos cualitativos en la comprensión del comportamiento humano. Es interesante conocer si los docentes aprecian esa vida que transcurre al margen del aprendizaje formal y si la consideran al planificar y organizar su trabajo de aula, tomándola como un reto importante para llevar a cabo una educación moral que considere el clima de aula y la atención a las relaciones humanas.

\section{3- Metodología}

La tarea de esta investigación es descubrir la naturaleza del aula y su clima a través de cómo la gente actúa y da sentido a esa realidad educativa. En la tarea el observador usará un conjunto de procedimientos interpretativos para identificar el sistema de convivencia, los intercambios lingüísticos, la distribución de los alumnos en el salón de clase, desde una perspectiva ética, en su uso práctico y concreto. Es un proceso abierto de observacióndescripción- análisis interpretativo- comprensión de los procesos implicados y se caracteriza por la presencia más o menos prolongada del investigador en el campo donde se realiza el trabajo. Por lo tanto tendrá una fuerte orientación empírica y descriptiva en la cual el detalle y las particularidades no serán dejadas de lado en las instancias de observación, entrevistas y de abordaje de las narraciones de los docentes.

\section{1- Técnicas de investigación}

Como cuestión estratégica se decide la siguiente secuenciación para la aplicación de las técnicas: las observaciones en el aula, las entrevistas a los alumnos, las entrevistas a los docentes y la solicitud de las narraciones.

Se elabora una planilla de observación que atiende los propósitos y alcances de nuestro estudio. En ella aparecen algunos indicadores que se agrupan según las áreas seleccionadas en esta investigación y que permiten captar aspectos relacionales y morales de los maestros y alumnos y hay lugares en blanco para anotaciones y registros que corroboran el valor de esta técnica.

Así el observador busca captar no sólo el comportamiento visible sino los significados transmitidos mediante la comunicación, identificando la cultura estudiada, reconociendo otros roles del contexto a partir de su participación, del vínculo que se establece según el mayor o menor grado de confianza entre los sujetos. La percepción del observador permite conocer las interpretaciones que ellos elaboran en sus prácticas cotidianas, captar sus experiencias y los significados sociales que construyen. Esos rubros no se establecen como definitivos ni acabados y muchas veces se hacen anotaciones al margen que luego se integran al documento. 
Para la entrevista de investigación se elabora una pauta semiestructurada y por lo tanto abierta y flexible. El objetivo es la generación de un discurso por parte del sujeto entrevistado a los efectos de poder aprehender sus ideas más profundas sobre el tema de trabajo. Los destinatarios de este instrumento son indefectiblemente los maestros y por lo menos dos alumnos por grupo elegidos a azar, más uno por grupo escogido por el investigador. Se obtienen cinco entrevistas a docentes de clase y veinte entrevistas de alumnos. Las entrevistas se amplían o reajustan en vista de nuestra población objetivo y de los objetivos del propio trabajo.

Se propone a los seis docentes que redacten situaciones y sucesos que han vivido en su aula y que pongan de manifiesto cuestiones morales..

\section{2- Las escuelas escogidas}

Se escogen tres escuelas urbanas comunes que presentan como características similares: número de alumnos entre 200 y 300; no cuentan con equipo multidisciplinario; poseen recursos didácticos suficientes para desarrollar su tarea; han diseñado un Proyecto de Centro propio; tienen una valoración positiva por parte del cuerpo de inspectores que las orienta y supervisa, fuerte identificación con su barrio, locales adecuados y en aceptable estado de conservación y fuerte apuesta a la participación y actualización docente.

Escuela A: Pertenece a la zona céntrica de la ciudad capital departamental, con un personal estable, experimentado y comprometido con la visión que la comunidad tiene de la institución. Es una escuela preferida por los docentes porque su historia, sus antecedentes y la propia ubicación determinan de hecho que todo está dado para facilitar su tarea y lograr un prestigio profesional.

La comunidad percibe la institución como prestigiosa socialmente más que pedagógicamente, presume la existencia de un Proyecto de Centro viable, adecuado a la comunidad y que comparte los objetivos educativos y morales con la misma, supone que allí los problemas y conflictos son mínimos y fácilmente superable, pero la intervención de esa comunidad en la vida escolar casi se refiere exclusivamente a eventos sociales y culturales.

Escuela B: Se ubica en un barrio periférico de la misma ciudad, cuyo personal varía casi en un 50\% cada año. Los docentes que aquí se desempeñan reconocen que realizar su tarea cada día es un verdadero desafío en cuanto a la asistencia, presentación, motivación y comportamiento de sus alumnos. En todas las clases hay alumnos con extraedad, con dificultades de aprendizaje, con situaciones socio-familiares deterioradas y con poca asistencia social, con aspecto -veces-, desaliñado y sucio y víctimas de violencia de diverso tipo. Han diseñado un Proyecto de Centro con énfasis en los valores y en el mejoramiento de las relaciones interpersonales a través de variadas actividades curriculares y extracurriculares con fuerte involucramiento y compromiso de los docentes con el mismo.

La comunidad en su mayoría más que esperar de la escuela la atención educativa y pedagógica, le demanda asistencia alimenticia, sanitaria, social y psicológica. La presencia de la familia es para reclamar, generar pleitos, agredir verbalmente a niños y familias, a veces incluso a las docentes y muy pocas veces para aportar ideas, colaborar o construir. Cuando aparecen éxitos académicos o culturales de la escuela también muy pocos los valoran en su justa medida. Esta comunidad pretende usar y abusar de la escuela y de sus posibilidades de servicio. 
Escuela C: Se encuentra en una pequeña ciudad distante a $40 \mathrm{Km}$. de la capital del Departamento. La mayoría de los docentes son efectivos y con años en la misma. Han diseñado un Proyecto de Centro en cuya elaboración y ejecución se involucran los padres, las fuerzas vivas, otras instituciones sociales y por supuesto todo el cuerpo docente. El mismo incluye variadas actividades: curriculares, extracurriculares, de extensión cultural en el medio y de reflexión, evaluación y seguimiento. La propuesta pedagógica recoge esta visión a pesar que la diversidad en las aulas presenta alumnos con capacidades diferentes, fuertes conflictos socio-familiares y de bajísimo nivel socio-económico.

La comunidad, en su mayoría participa de la vida escolar, conoce de cerca la realidad institucional y áulica. Concurre para demandar y para aportar, se hace responsable de los éxitos y de las dificultades que los reconoce y actúa en consecuencia. Conforma un verdadero entramado socio-cultural con otras instituciones del medio para sostener y acompañar la acción y la vida de la escuela. Colabora en la medida de sus posibilidades con todas las actividades sin desconocer que lo prioritario es lo educativo-formativo. Seguramente apuesta a una verdadera realización personal de los educandos a través de la escuela.

\section{3- Grupos de estudio}

De cada una de las escuelas seleccionadas se trabaja con un grupo de tercer año y un grupo de cuarto año de Educación Primaria (niños entre 8 y 10 años), totalizando seis clases.

Los docentes tienen muy diferentes características tanto personales como profesionales: edad, antigüedad docente, experiencia en el grado, permanencia en la escuela y carácter del cargo.

La adhesión de los maestros es tácita y franca lo que motiva acercamientos informales donde se explican los propósitos y el alcance de este trabajo. Luego de esto queda totalmente franqueada la puerta del aula.

\section{4- Cuadro de Datos del Trabajo de Campo}

\begin{tabular}{|l|l|l|l|l|l|l|}
\hline Clase & & $3^{\circ}$ & & & $4^{\circ}$ & \\
\hline Escuela & A & B & C & A & B & C \\
\hline Alumnos & 22 & 34 & 25 & 24 & 30 & 32 \\
\hline Alumnos entrevistados & 3 & 3 & 3 & 3 & 4 & 4 \\
\hline Maestros entrevistados & 1 & 1 & 1 & - & 1 & 1 \\
\hline Maestros entrevistados efectivos & 1 & 1 & 1 & - & 1 & - \\
\hline Antigüedad docente & 27 & 9 & 7 & 29 & 5 & 8 \\
\hline Antigüedad en la escuela & 8 & 3 & 2 & 6 & 1 & - \\
\hline Narraciones aportados & 1 & 1 & 2 & - & 1 & 1 \\
\hline
\end{tabular}

A los efectos de clarificar las citas que aparecerán, se elaboran los siguientes códigos:

Observaciones de clase $N^{0} 3$ - (Ob-3); Entrevista a alumnos $N^{\circ} 6$ - (en6), Narraciones de docente $\mathrm{N}^{\circ} 1-(\mathrm{N} 1)$; Entrevistas al docente $\mathrm{N}^{\circ} 2-(\mathrm{em} 2)$ 


\section{4- El desafío de cada día}

Bajo este título se organiza el resultado del análisis de los datos obtenidos en el trabajo de campo. Luego de un arduo trabajo de reflexión y estructuración se establecen cuatro dimensiones de análisis:

La primera: "La visión de la escuela", en ella se integran una serie de recurrencias que tienen que ver con la realidad construida en aspectos teóricos, la propia acción, y la percepción de lo que es y debe ser la escuela, la acción de los docentes y las vivencias que deben darse en el aula. A la vez que un producto de esta interacción, la visión influye en la vida diaria y se hace presente en las tareas que se van incorporando año a año a la escuela, en las estrategias que se eligen para enfrentar sus debilidades y resolver las demandas, por lo tanto la visión es un marco de referencia, señala la intencionalidad y da sentido al trabajo. Estos supuestos permiten tomar decisiones en temas como la promoción, la selección de contenidos, la asignación de maestros a los grupos, el uso del tiempo y el lugar del maestro de clase en la institución. Tener la visión de escuela también implica la percepción de los involucrados de qué es la escuela, qué le corresponde hacer, cuáles son sus áreas de intervención y cómo estos aspectos se revelan y develan en la vida cotidiana donde la socialización y la educación en valores aparecen reiteradamente como fines socialmente enfatizados. Todo ello en un interjuego entre lo académico y lo ético que cobra fuerza a lo largo de este trabajo a través de apreciaciones que alternativamente priorizan uno u otro aspecto.

Aquí aparecen cuatro categorías que se han denominado: El rol docente: (la trasmisión del conocimiento, la atención a las dificultades y la reflexión sobre los alumnos) sobre el que expresan: "en este medio el rol docente se está desvirtuando porque el rol nuestro que es enseñar...se vuelve asistencialista (em3)... y que también pasa por el plano del desarrollo de competencias cognitivas y de aprendizaje, de normas de convivencia, que propone que la escuela sea modelo en un mundo con pocos modelos y que los niños sientan placer por asistir, compartir y aprender". La organización de la clase: (la articulación de los elementos y actores que intervienen, lo curricular y lo académico, la administración de las energías), este aspecto difiere notoriamente del imaginario que cada docente o niño crea, en él intervienen desde supuestos teóricos como el diseño y la planificación en conjunción con lo físico y humano del aula requiriendo una gran dosis de administración y regulación: "hay dificultades para articular lo curricular con los sucesos del aula porque a veces se trae la planificación y uno se encuentra con otra cosas que surgen, cosas que hay que abordarlas con los niños"(em3).Una tensión no menor a resolver por parte del maestro es la existente entre el currículo prescripto y las demandas reales del entorno, que implica el manejo de los espacios y de los tiempos y la administración de las sinergias del aula: "es bastante difícil llevar a cabo la actividad en ese clima (hostil), es muy difícil, uno conversa con ellos...hay que organizar el trabajo...volver a intervenir."(em2) Lo que hay que aprender:( las propuestas áulicas y el contenido de la acción), en el aula los alumnos viven sucesivas experiencias que promueven la obtención de conocimientos conceptuales (a dividir, multiplicar y los problemas".(en12), procedimentales y actitudinales provenientes de lo prescripto o del propio contexto de la institución, "aprendieron a escuchar, a ser escuchados, a respetar, a emitir opiniones y juicios, a reflexionar y a que hay una escala de valores que debe ser respetada por vivir en sociedad(N2).

Esas expectativas de logro confieren una visión realista y confiada frente al futuro en una proyección que se hace: "aprendí que la vida hay que vivirla, si no la vivís y no te comportás como tenés que comportarte, no vas a llegar muy lejos; tenés que esforzarte, si no podés tá', pero tenés que esforzarte(en18). Lo que hay que enseñar: (la socialización primaria en pugna con la secundaria, lo que la escuela y clase deben dar), estos aspectos exigen que lo que se enseñe esté cargado de vivencialidad, deben aparecer como valiosos y aplicables a su propia 
vida y promover el interés de tal modo que lo pueda llevar a separarse de sus objetos naturales y cercanos, "con la maestra hablamos de la disciplina y que nos mantengamos tranquilos y ella habla afuera con los que se portan mal y les explica sobre eso"(en4) para apoderarse de otros más distantes y abstractos. Es necesario que la propuesta ofrezca a los niños experiencias que permitan construir nuevas identidades y capacidades "que por lo menos ellos me escuchen a mí, aquellas cosas que de pronto estén bien...o que están mal, los límites adecuados porque a veces los padres no pueden estar con ellos(em1) y que la intervención pedagógica deje huellas profundas en su formación: "nosotros debemos enseñar ética con ética"(N2); aun así se pretende que el tiempo de enseñar sea mayor que el dedicado a disciplinar.

La segunda dimensión describe lo que sucede "Más allá del aula", ésta no como un ambiente independiente sino relacionada con la escuela, la familia y el medio, que a su vez determinan presiones y reacciones propias. Incluye dos categorías: El aula y su entorno: (la articulación con otros ambientes y actividades de la escuela, el discurso y la práctica docente, el establecimiento de los límites, la relación con la familia), los aspectos más notables se observaron en el enmarcamiento de las interacciones entre maestros y niños, particularmente en relación a la legitimidad atribuida en el discurso docente a las prácticas culturales locales "muchas cosas suceden por falta de diálogo en la familia, allí no hay límites y los niños no están contenidos...hay que involucrar a la familia, la comunidad, para que entiendan que la educación es tarea compartida y que los padres delegan en la escuela más responsabilidades de las que le corresponden". Los acuerdos y el consenso: (hábitos, comportamientos y actitudes acordadas que promueven la realización de los alumnos), no puede quedar fuera de este estudio lo que denota y connota el acto educativo. Las vivencias del aula seguramente tienen propósitos y objetivos educativos ya que le es totalmente inherente, y lo define en situaciones en que "la maestra muchas veces hace referencia a reflexiones anteriores sobre el comportamiento y a lo pactado en sucesivas oportunidades para lograr el orden, los alumnos lo reconocen y asienten, pero a los pocos minutos parece que lo olvidan"(Ob-2). Lo colaborativo, lo cooperativo y lo humano: (las relaciones del aula se basan o no en la autoridad, cuando el diálogo y el acuerdo fortalecen la convivencia), cuando en el aula se observan las relaciones entre los alumnos y los maestros no siempre se basan explícitamente en la autoridad sino en el diálogo y en el acuerdo, "los mejores preguntan: ¿a quién ayudo? Y ellos se sienten importantes no así de sentirse superiores, sino del aspecto cooperativo.... Hay niños que ofrecen su ayuda hasta fuera de hora, al recreo y así colaboran con sus compañeros"(em1).

La tercera dimensión encierra conceptos que tienen que ver con "La unidad y la diversidad" en cuanto a la articulación y tensión entre las individualidades y el grupo ya que no hay duda que los valores se enseñan desde que se nace, siendo muy poderosos los mensajes de los "enseñantes colectivos" porque los presenta como condición de pertenencia. Es decir, si no se acepta la guía de valores que reúne un colectivo social, en este caso el aula y la escuela, no hay pertenencia. Confesar esos valores aparece como una condición para no quedar fuera, para no ser excluido; ésta es sin duda una enorme presión que en la edad escolar puede no ser consciente. Esta dimensión incluye dos categorías: la pertenencia y la autonomía: (cómo juegan los niños y los maestros en un sistema de relación con autoridad tácitamente establecida en la cual la posición de los alumnos puede cobrar o no una dimensión relevante). Todo colectivo social está en riesgo de inculcar su selección de valores a sus miembros y hasta tal punto es así, que aquel que quiera construir con cierta autonomía su propia escala de valores debe aceptar la tensión y conflicto entre autonomía y pertenencia, esto directamente relacionado con los niveles de integración y consistencia de los vínculos sociales del grupo, algo que los contratos no podrán construir. El desafío es la construcción de la unidad desde la autonomía; 
esta unidad en la libertad se verifica cuando el grupo se da, como tal, permisos para la diferencia y lo consigue cuando incluye ciertos grados de incertidumbre y azar en su propio diseño. "Todas las escuelas tienen problemas de disciplina, condiciones desestimulantes, niños agredidos, niños agresores, violencia...sobre los que se debe intervenir, donde los criterios y juicios los establecen los maestros en función de las normas explícitamente puestas por los propios maestros ...la distensión del maestro es la distensión de la clase". (N2) La comunicación en el aula: (el complejo sistema de relaciones que crean y acuerdan y las formas de comunicación que con la impronta de cada día presentan una dinámica muy interesante), "la maestra trata de hablar con claridad para sus alumnos, reitera expresiones y las explicita de diversas formas...en situación de enseñanza el lenguaje de la docente se escolariza y se hace propio del tema que trata. La expresión no es totalmente rígida y a través de sinonimia pretende ser atendida y entendida. Estos espacios de actividad son breves y la docente procura el mayor aprovechamiento del mismo".(Ob-1). "Los gestos son de todo tipo. se observan en todos los subgrupos de la clase; los hay de burla, de indiferencia, de agresión, obscenos y alguno de aprobación"(Ob-5) La diferente forma, cantidad, variedad y calidad de mensajes que se viven, expresan o recepcionan en el aula tienen potente significado para los participantes que construyen una serie de valoraciones en cuanto su contenido y uso porque constituirán su acervo para la vida de relación en ámbitos más amplios de su vida cotidiana y adulta.

La última dimensión se denomina "La ayuda situada" e intenta tener en cuenta la dinámica de las situaciones que se dan en el aula en beneficio de los procesos de aprendizaje. Rescata aquello de que toda situación de aprendizaje exige un clima relacional afectivo y emocional basado en la confianza, la seguridad, la aceptación del otro, y en el que tengan cabida la curiosidad, la capacidad de asombro y la promoción del interés por el conocimiento; aspectos visibles o invisibles, verbales o gestuales. Se presenta en dos categorías: Los sectores del aula: (la consideración de las diferencias individuales y la observación de subgrupos del aula desde el punto de vista relacional y didáctico para fortalecer lo positivo y diluir lo negativo), los alumnos en esta etapa requieren la consideración y el acompañamiento del adulto para actuar y adecuarse a sus condiciones individuales, ya que no disponen de estrategias de comprensión y asimilación autónomas. Para ello las docentes organizan grupos de interacción a partir del conocimiento de las posibilidades cognitivas y las capacidades vinculares de los integrantes de la clase alentados hacia una disposición positiva para esa integración por parte de los maestros: "claramente se reconocen sectores de alumnos, los muy buenos, los de rendimiento medio y los varones que se agrupan espontáneamente...los grupos están claramente estructurados y la afinidad se establece por el nivel socioeconómico, por sexo o por nivel de rendimiento".(Ob-4) Los momentos áulicos: (las formas de establecer las actividades y propuestas más allá de los contenidos). El buen criterio docente advierte que el maestro debería: ejercer la autoridad tomando decisiones y orientando la actividad, lograr la producción individual y colectiva del grupo, asegurar la igualdad de oportunidades y evitar frustraciones en sus alumnos. La consistencia entre el decir y el hacer del docente juega un papel importante en la credibilidad del profesional, en la confianza de los alumnos hacia su maestro y en la importancia que adquiere el aprender para los involucrados. "La clase es bochinchera y a veces tranquila; algunos compañeros hacen bochinche y conversan demasiado. La maestra rezonga y algunos niños no pueden concentrarse. Algunas veces hay discusiones y hasta gritan, no hacen nada (agresivo) a los compañeros, pero insisten con eso. Los que se portan bien se callan y trabajan, están sentados. Piden a los otros que se callen diciendo que quieren trabajar. Yo opino que hay que callarse porque hay niños que piensan y se concentran y así se trabaja mejor y sería una clase mejor"(en15). La actividad en el aula deja de manifiesto la sinceridad en el humilde reconocimiento de las propias fragilidades y virtudes de todos la que la integran: "Pusimos paciencia y tiempo para conocernos en esas conversaciones, con alguno se hizo en forma individual, en otras grupal, siempre para superar algún conflicto y aun desplazando lo 
curricular":(em4). "Todas (las maestras) me enseñaron o trataron de enseñarme, pero la de segundo me gustó más porque cada día ponía una sonrisa en nuestra cara y nos alentaba". (en17).

En cada uno de los apartados anteriores las consideraciones o conclusiones primarias son muy cercanas a la empiria y la construcción de la teoría se enriquece con los aportes de Berger y Luckmann, Edgar Morin, César Coll y Basil Berstein.

\section{Conclusiones}

Las conclusiones sin ser definitorias ni determinantes, reafirman la complejidad, amplitud y apertura del tema y dejan abiertos caminos de reflexión y elaboración para siguientes investigaciones.

Este trabajo de investigación nos permite realizar las siguientes apreciaciones, -algunas muy simples-, pero consideramos interesante dejarlas escritas:

= Buscar lo moral y lo ético en el aula es como colocarse y mirar desde la trastienda procurando no dejar escapar nada a nuestra mirada.

= Las cuestiones morales y éticas, +siempre están en el aula.

= Los docentes, por lo general, eluden las cuestiones morales y éticas y no reflexionan sobre este aspecto de su quehacer docente.

= Cuando los docentes reflexionan sobre temas morales y éticos asumen posturas de víctimas o de culpables y eventualmente de críticos.

= El abordaje de la Educación Moral lo realizan a través de teorías y de contenidos, pero esporádicamente a través de la reflexión sobre la propia práctica.

= Aún no se ha salido totalmente de la contemplación pasiva para pasar a la conciencia expresiva en relación con los conflictos, los problemas interpersonales y situaciones de segregación en las aulas.

= Ante las situaciones señaladas anteriormente, los docentes generalmente las narran y las describen del punto de vista psicológico y/o sociológico y no del punto de vista ético.

= Son escasas las experiencias de reconstrucciones e interpretaciones de los conflictos en este marco teórico.

= Existe un debilitamiento del grado de confianza hacia el maestro por parte de los niños y sus familias.

= La escuela se siente sola e impotente ante la problemática de sus alumnos.

= Se muestra como una gran dificultad la consideración de las "marcas" morales que deja en los niños la vida en las aulas.

En un plano de reflexión más profundo nos permitimos sostener:

$=$ Existen evidencias para sostener que los maestros son conscientes de pertenecer a una cultura diferente en relación con la cultura de los niños. Esta diferenciación cobra sentido en la definición de qué hace y debería hacer la escuela.

= Tanto los maestros como niños expresan que a partir de esa cultura heredada de las familias, y con la intención de ampliarla, enriquecerla o cambiarla, la función de la escuela y el rol de los maestros es la formación integral, apuntando a lo académico; la preparación y las conductas para la vida; la actividad laboral; las conductas de relacionamiento con otras personas y la realización personal. 
= Las diferencias y regularidades que distinguen al clima de aula en variadas dimensiones se visualizan y realizan en el proceso de construcción del conocimiento, diferenciación y reflexión, y a través de un constante movimiento, de una oscilación entre polos opuestos como la calma y el desorden; la estabilidad y el caos; la autoridad y la disciplina; el presente y el futuro; lo que se debe hacer y lo que hay que hacer; el contenido y la forma; lo personal y lo social; lo implícito y lo explícito; lo correcto y lo incorrecto; lo objetivo y lo subjetivo; la crítica y la autocrítica...

= Creer que las matrices personales y sociales de valores se construyen sólo en los horarios escolares, dentro de los salones de clase, en los recreos, es una creencia ingenua.

= Se espera que la escuela en cuanto a la apropiación de valores; responda con un plan bien diseñado, con sus etapas anticipadas, con su cronograma, con una descripción de los cambios que deseamos como objetivos y con los indicadores que nos darán noticia de que los mismos se han producido en adultos y niños

= Se reconoce que existen modos formales, no formales e informales; explícitos e implícitos de transmitir valores.

= Hoy son muchos los que enseñan; muchos más que la escuela y la familia y hay que tener en cuenta los mensajes valorativos que las nuevas tecnologías de la comunicación hacen llegar simultáneamente a todos en todos los rincones del planeta. También llegan mensajes de las prácticas sociales, del grupo de pares, de sus familias, de otras culturas... Ese mensaje plural no es coherente ni sistemático. A los niños de hoy les llegan guías de valores distintas, contradictorias, deshilachadas. Las voces de los adultos no logran armonizar un mismo discurso, parece que hay (o hay) muchos discursos; no hay una orientación acordada y por lo tanto aparece la confusión y el pluralismo a gran escala.

= La escuela cumple una tarea indispensable, pero se sitúa en un contexto intercultural que también enseña valores. En las escuelas también está presente la cultura institucional de cada centro, construida a lo largo de su historia en un entorno territorial y social determinado y se hacen presentes, además las pautas culturales propias del entorno social próximo a la escuela, así como la cultura critica de la ilustración y su mandato emancipador que es el sostén básico de las sociedades democráticas con su mensaje universal sobre los Derechos del Hombre; se trata entonces de que existen muchos emisores que trabajan en simultáneo, y a veces con mayor fuerza, en la emisión del mensaje escolar.

= El gran valor de los involucrados en la acción educativa está en su interjuego, en el valor de la experiencia personal e íntima; en la construcción de la autonomía moral, en la relación con las exigencias del contexto social como condicionante y determinante de la misma.

= Hablamos de personas, de seres humanos, de proyectos de vida, de procesos intencionales, de verdaderas construcciones vitales y no sólo de procesos discursivos, de universo de palabras.

$=$ Las actitudes y los valores que se ponen en funcionamiento en las aulas admiten ser revisados, esclarecidos, evaluados, corregidos, afianzados. Seguramente aparecerán y encontraremos nueva bibliografía para avanzar y profundizar en el tema o emprender otras investigaciones para complementar este abordaje.

No son las conclusiones de esta investigación un manual tecnológico de procedimientos para luego ser aplicados en las aulas. Son el punto de partida hacia un debate, de múltiples posturas posibles. Por lo tanto, no existe la pretensión de cerrar la discusión. Si sirve de consuelo, es bueno reconocer que estos cuestionamientos se encuentran en la mayoría de los docentes, porque la enseñanza de los valores que sustenta el abordaje ético del clima del aula se encuentra sobre la mesa, en un estado de debate y, por suerte, no se sale de él. 


\section{Bibliografía citada}

Berger, P.; Luckmann, T.1968. La construcción social de la realidad. Buenos Aires. Amorrosrtu.

Bernstein, B. 1993. La estructura del discurso pedagógico. Madrid. Morata.

Bourdieu, P.; Passeron, J.C. 1977. La Reproducción. Barcelona. Laia.

Bruner, J. 1997. La educación, puerta de la cultura. Madrid. Visor.

Bruner, J.1966. Desarrollo cognitivo y educación. Madrid. Visor.

Camilloni. A. y Otros.1996. Corrientes didácticas contemporáneas. Buenos Aires. Paidós.

Gimeno Sacristán, J; Pérez Gómez A. 1993. Comprender y transformar la enseñanza. Madrid. Morata.

Giroux H. 1992. Teorías y resistencia en educación. México. Siglo XXI.

Jackson, P. 2002. Práctica de Enseñanza. Buenos Aires. Amarrortu.

Jackson P.; Boostrom R. Hansen D. 2003. La vida moral en la Escuela. Buenos Aires. Amorrortu.

Jacobson R. 1976. Nuevos ensayos de la lingüística general. México. Siglo XXI.

Vigotsky L. 1984. El desarrollo de los procesos psicológicos superiores. Barcelona. Grijalbo.

Wittrock, M. 1989. La investigación en la enseñanza I-Métodos cualitativos y de Observación. Ecuador. Paidós.

\section{Bibliografía consultada}

Aguerrondo I.1991. Innovación y Calidad de la Educación. Revista de OEA. Buenos Aires. Bruner, J.1991.Actos de significado. Madrid. Alianza Editorial.

Bruner, J.1988. Realidad mental y mundos posibles. Barcelona. Gedisa.

Carr, W.; Kemmis, S.1988. Teoría Crítica de la Enseñanza. Barcelona. Martínez Roca.

Carr W.1990. Hacia una ciencia crítica de la educación. Barcelona. Laertes.

Devereux, G. De la ansiedad al método en las ciencias del comportamiento.

Díaz Barriga, A. Didáctica. Aportes para una polémica.1991. Buenos Aires. Aique.

Díaz Barriga ,A. Didáctica y Curriculum. 1994. México. Nuevomar.

Escudero, J.1988. La innovación y la organización escolar, en R. Pascual. (Ed) La gestión educativa ante la innovación y el cambio. Madrid. Narcea.

Freire, P. 1999. Pedagogía de la autonomía. Buenos Aires. Siglo XXI.

Frigerio, G; Poggi, M. Cara y Ceca.1992. Buenos Aires. Editorial Troquel.

Gaulejac, V. 1993. La sociología y lo vivido,en "Sociologies Cliniques". París. Ed.Hommes \& Perspectives.

Gimeno Sacristán, J. 1989. El currículum: una reflexión sobre la práctica. Madrid. Morata.

Gimeno Sacristán, J. Teoría de la Enseñanza y desarrollo del curriculum.1986. Buenos Aires. REI.

26 - Universidad ORT Uruguay 
Hargreaves A. 1996. Profesorado, cultura y postmodernidad: cambian los tiempos, cambia el profesorado. Madrid. Morata.

Jackson, P. 1999. Enseñanzas Implícitas. Buenos Aires. Amorrortu.

Jackson, P.1990. La vida en las aulas. Madrid. Morata.

Litwin, E. 1997. Configuraciones didácticas. Paidós. Buenos Aires.

Litwin, E.!998. La investigación en un debate contemporáneo. En Carretero M. El debate constructivista. Buenos Aires. Aique.

McEwan, H; Egan, K.1995. La narrativa en la enseñanza, el aprendizaje y la investigación. Buenos Aires. Amorrortu.

Meirieu P. 1992. Aprender, Sí. Pero ¿cómo? Madrid. Octaedro.

Mercer N. 1997. La construcción guiada del conocimiento. Barcelona. Paidós.

Morín, E.1990. Articular los saberes. La antigua y la nueva transdisciplinariedad, en "Science avec Conscience". París. Sevil.

Morín, E.1998. La cabeza bien Puesta. Barcelona. Gedisa.

Morín, E. 1990. Introducción al pensamiento complejo. Barcelona. Gedisa.

Pérez Gómez, A.1998. La cultura escolar en la sociedad neoliberal. Madrid. Morata.

Perkins, D. 1995. La escuela inteligente. Madrid. Gedisa.

Perrenoud, P. 1990. La construcción del éxito y del fracaso escolar. Madrid. Morata.

Sautu, R. 2003. Todo es teoría. Acerca de lo qué es y no es investigación científica en ciencias sociales. Buenos Aires. Lumiere.

Savater, F. 1997. El valor de educar. Madrid. Ariel.

Taylor, S.J; Bogman R. 1984. Introducción a los métodos cualitativos de investigación. Buenos Aires. Paidós.

Valles, M. 1997.Técnicas cualitativas de investigación. Madrid. Síntesis.

Wassermann, S, El estudio de casos como método de enseñanza. Buenos Aires. Amorrortu.

Wiggins,G.1993. Assessment: Authenticity. http://ericae.net/edo/ED328611.htm>.

Wittrock, M. 1989. La investigación en la enseñanza II-Enfoques, teorías y métodos. Ecuador. Paidós.

Wittrock, M. 1989. La investigación de la enseñanza III - Profesores y alumnos. Ecuador. Piados.

*El Artículo se enmarca en la tesis de maestría de la autora, dirigida por la Dra. Edith Litwin. Año 2005.

\footnotetext{
** Master en Educación. Universidad ORT. Diploma en Educación, Universidad ORT. Maestra en Educación Común. Instituto Formación Docente, Florida. Maestra especializada en Educación Especial, Instituto Magisterial Superior. Maestra Directora en Educación Común, Instituto Magisterial Superior. Docente, Instituto de Formación Docente. Canelones.
} 